\title{
RESEÑA DE LIBROS
}

David Barkin (con la colaboración de Adriana Zavala), Desarrollo regional y reorganización campesina. La Chontalpa como reflejo del problema agropecuario mexicano, México, Editorial Nueva Imagen, $1978,173 \mathrm{pp}$.

El libro que se comenta abarca un conjunto muy amplio de problemas que actualmente configuran la situación regional y agrícola de México. Por tratarse de una experiencia realizada en una zona del trópico húmedo, se vincula con la problemática económica y ecológica relativa al desarrollo de dichas zonas.

El análisis se limita a la temática del desarrollo regional. A este respecto, el libro de Barkin aporta un conjunto interesante de ideas è informacio nes para lo que debe ser una reformulación teórica de la política regional, de sus funciones y efectos en el desarrollo del capitalismo mexicano.

$\mathrm{Al}$ parecer, los programas regionales de desarrollo agropecuario han sido generados para cumplir dos funciones esenciales: la producción de divisas, por medio de la exportación de sus productos, que coadyuven al desarrollo industrial, y la producción de alimentos baratos para mantener bajo el valor de la fuerza de trabajo industrial. En este sentido, los programas tienden a reorganizar las producciones regionales para adecuarlas a las necesidades del desarrollo nacional, es decir de los sectores económicos predominantes en el proceso de acumulación de capital a nivel nacional.

En el libro que comentamos se puede observar con claridad cómo un programa de desarrollo regional puede vincularse con los intereses regionales, en tanto desarrollo de las fuerzas productivas locales e iniciación de cierto proceso regional de acumulación, y transformarse, en razón de la lógica de la expansión del capital en la sociedad mexicana, en un programa destinado en esencia a articularse con el desarrollo a nivel nacional e internacional, subordinando los intereses de las fracciones sociales localizadas en la región.

Esta formulación, al vincularse con lo que pudiéramos llamar la relación (contradictoria) entre desarrollo regional y desarrollo nacional, es imprescindible para conocer las posibilidades de un real desarrollo regional en la presente fase del desarrollo de la sociedad mexicana.

Veamos brevemente el proceso del Plan Chontalpa. Se crea en 1963 como parte del esfuerzo público para modernizar el agro, es decir como parte de la expansión del capitalismo en el conjunto del territorio nacional.

El programa original, que nunca llegó a cumplirse, preveía el reacomodo de la población de la zona para aprovechar la tierra disponible en forma intensiva, el desarrollo de cultivos perennes y de ciclo corto para garantizar la ocupación de la población durante gran parte del año y la utilización de una proporción pequeña de la tierra $(21 \%)$ en la ganadería. La producción 
estaría compuesta de manera fundamental por maíz, frijol, cacao, plátano, caña de azúcar, café y frutales.

Los objetivos suponían una reestructuración regional que aumentase la producción agrícola, manteniendo la producción regional de los principales alimentos utilizados por los pobladores.

Mientras el programa fue definido de esa forma se presentaron problemas con su financiamiento, "las instituciones crediticias aparentemente obstaculizaron los programas de producción limitando la oferta de crédito para expandir las áreas agrícolas, tal como se había aprobado originalmente" (p. 60).

Es interesante observar cómo en razón de ciertas causas regionales, pero de manera fundamental por las presiones que la economía nacional, y aun la internacional, ejercieron sobre el plan, éste se transformó en forma radical y empezó a recibir desde entonces un apoyo financiero sumamente importante.

En tal sentido el incumplimiento del plan tal como había sido diseñado originalmente, se habría debido a "los conflictos entre sus objetivos originales (basados en una planeación regional y local) y las demandas del sistema nacional que impedían el cumplimiento de estas metas..." (p. 61). A partir de 1971 se reorienta el plan y de manera progresiva aumentan los créditos disponibles. Toda una serie de cambios institucionales, igualmente instrumentados en esas fechas, alteraron la organización del plan de modo tal que se le destinó principalmente a la producción de ciertos productos vinculados con el proceso nacional de industrialización y las necesidades del mercado externo. En esencia, el área productiva de La Chontalpa se destinó a la producción ganadera y de la caña de azúcar abandonándose los otros tipos de cultivos. La producción se orienta a atender las necesidades de la exportación (sustituyendo en el mercado interno al ganado del norte que se exporta a los Estados Unidos, y a la caña de azúcar, cuya producción iba en descenso obligando su importación) y a lo que pudiéramos llamar el mercado suntuario (urbano) de alimentos.

Los cambios producidos en la estructura productiva regional, al ser orientados en función de los intereses "nacionales" provocaron una serie de consecuencias "negativas" en la región. En definitiva se trató de las consecuencias necesarias a la incorporación de la región en el mercado nacional y por ende en el proceso de acumulación de los sectores económicos predominantes a nivel nacional. Por ejemplo, al generarse una baja en el grado de autosuficiencia de la población, la dieta ha desmejorado. No se dispone de animales domésticos y hortalizas producidas en las huertas familiares (dado el proceso de proletarización de la población que provocaron los cambios mencionados), y los alimentos se obtienen de otras regiones, por los canales comerciales, con la consabida disminución en sus valores nutritivos. Por otra parte, se produce una fuerte diferenciación socioeconómica entre algunos socios de los ejidos colectivos, que además poseen tierras privadas y se enriquecen relativamente, y la mano de obra "libre" que es contratada para la realización de ciertas labores, por lo general, temporales.

En suma, la ejecución del plan introdujo a la producción de La Chontalpa en la lógica de desarrollo del capitalismo, colocándola en una posición subordinada respecto de los sectores productivos predominantes, cumpliendo 
una función articulada a las necesidades concretas que para esos sectores genera la situación económica mexicana desde mediados de los años sesentas.

De este modo, se presenta lo que pareciera ser una contradicción necesaria entre los intereses de las fracciones sociales regionales y los de las "fracciones nacionales". Dentro de esta contradicción se ubican las experiencias denominadas de desarrollo regional. A partir de estas situaciones deberá, entonces, considerarse la posibilidad de políticas e instrumentos que se destinen de manera efectiva a mejorar las condiciones de vida de las poblaciones localizadas en las llamadas regiones no desarrolladas, a provocar procesos de desarrollo que no subordinen sus producciones a intereses de otras fracciones sociales y a contribuir, de igual forma, al desarrollo nacional.

En este sentido se vislumbran por lo menos dos áreas problemáticas. Por una parte, producción de alimentos que debe garantizar mínimamente la reproducción material de la población campesina del conjunto del país, como una meta principalísima de toda la política. Junto a esto, los interrogantes acerca de si el modelo de desarrollo imperante, y su distribución de posiciones para las distintas producciones regionales, puede garantizar la satisfacción de esa necesidad fundamental. Desde nuestro punto de vista, ésta es la problemática fundamental que está en juego al analizar un plan como el de La Chontalpa, y a partir de ella debe ser percibida tanto su significación actual como las propuestas futuras.

E1 libro que ofrece Barkin incorpora, en este centro temático, un conjunto de aspectos que permiten además una visión integrada de un plan regional y de su significación nacional.

Pedro Pirez

El Colegio de México

José Giral, Sergio González, y Eduardo Montaño, La industria química en México, México, Redacta, 1978, 343 pp.

Como en un intrigante movimiento pendular, la literatura latinoamericana sobre los "grandes temas" (desarrollo, ciencia, tecnología, planificación, nuevo orden económico internacional) asciende hacia un extremo que consideramos afortunado. Tiene cuatro características este movimiento. En primer lugar, advertimos un énfasis justificado en la conducta microeconómica en contraste con la visión global que había prevalecido hasta los últimos años. Segundo, captamos que las variables internas de los procesos socioeconómicos y tecnológicos merecen ahora mayor escrutinio. Atribuirle origen externo a cualquier problema nacional fue una interpretación correcta hasta cierto punto; pero también fue incompleta y escapista. Era menester explorar las causas y la dinámica que se verifican en el interior de los países y como consecuencia directa de políticas nacionales. En tercer lugar, las exploraciones no se están deteniendo en la etapa sectorial - lo cual es ya un avancesino que tocan las componentes intra e intersectoriales. De este modo se pueden obtener pistas más claras acerca de los obstáculos y las carencias del 
desarrollo industrial, tecnoeconómico, etc. Por último, la investigación pertenecía a "lobos solitarios" que solían arrancar aquí y acullá algún trozo de sabiduría o desbarrancarse en un tremendo error; ahora despunta una sana tendencia al trabajo de equipo que permite la complementación disciplinaria y el control mutuo de inclinaciones sesgadas.

Estos cuatro rasgos aparecen nítidamente en esta excelente obra que se refiere no sólo a la evolución de la química en México, sino que aborda también cuestiones más generales vinculadas con la "investigación de la investigación", vale decir, el flujo de innovaciones, la formación de capital humano, las restricciones que dimanan de la escala y el capital financiero, el peso de los insumos complementarios, los estilos de planificación y "subplanificación", la saturación tecnológica, y otros asuntos conexos.

Ciertamente, este libro no se ha desprendido totalmente de las características no tan felices que modelaron otras situaciones intelectuales. Por ejemplo, el enciclopedismo, esto es, el afán de abrazar todos los aspectos posibles de la actividad química en México (históricos, arqueológicos, económicos, ingenieriles, científicos) es todavía muy fuerte. $\mathrm{Y}$ este enciclopedismo no permite observar con facilidad los hilos conductores de la obra; le resta selectividad y acaso profundidad. Sin embargo, tomada y evaluada la obra en su conjunto se trata de un defecto menor.

Contiene tres partes y 18 capítulos. La primera examina aspectos generales concernientes a la historia de las actividades químicas en México, los factores que la incentivaron e inhibieron, el marco mundial de referencia, las dimensiones económicas, y los recursos naturales y humanos disponibles. La segunda parte se embarca en el análisis intrasectorial, sugiriendo una interesante tipología entre industrias de proceso, industrias de producto, de operación y de equipo. Las peculiaridades de cada una de ellas son apuntadas con tino. La última parte del libro se refiere a las perspectivas de este quehacer. Aquí se coloca el acento en los "exponentes de escalación", en la evolución probable de los mercados internos y externos, y en los requisitos tecnológicos futuros en la industria química. Esta obra contiene, además, 12 apéndices que la complementan y enriquecen.

Al pasar revista a este análisis me concentraré en tres temas que considero de singular importancia y generalidad: los recursos humanos, la concepción del desarrollo tecnológico que presentan los autores, y la evaluación de las perspectivas de esta actividad.

Los tres analistas destacan con razón la importancia cardinal de los recursos humanos en el avance de la química. Sin ellos, y sin configuraciones organizacionales adecuadas (como las que se presentaron en la experiencia alemana del siglo pasado), la química no hubiera podido ofrecer las ramificaciones y aplicaciones que hoy exhibe. En México, los ingenieros químicos forman el grupo más amplio de esta familia profesional. Se ocupan de menesteres tan diversos como los alimentos, el proceso metalúrgico, la contabilidad en empresas complejas, y la refinación del petróleo. No son un grupo ocupacional homogéneo. Y sin embargo, los métodos de entrenamiento profesional no reflejan esta flexibilidad; antes al contrario, son rígidos y tradicionalistas. De esta suerte se gesta una brecha cualitativa entre la unidad formativa (universidades) y el mercado. Los autores apuntan la existencia de esta brecha, pero no exploran cuidadosamente sus orígenes y resultados. Indi- 
can, es verdad, que se verifica un "éxodo de cerebros" interno entre las desiguales actividades que los químicos efectúan. Sin embargo, se abstienen de averiguar las causas del hecho. Lástima. Pues este tipo de análisis - si se hubiera realizado- habría puesto al descubierto las motivaciones, recompensas y castigos inherentes al papel del químico en una sociedad en desarrollo y expansión tecnológica.

La industria química mexicana es francamente intensiva en capital. En el periodo 1970-1975, se invirtieron en ella cerca de 35 mil millones de pesos; a precios constantes de 1977, la inversión podría llegar en 1982 a los $100 \mathrm{mil}$ millones, debido a los progresos de la petroquímica básica y secundaria. Estos formidables requerimientos financieros se traducen en el alto costo de cada lugar de trabajo que gira entre $300 \mathrm{mil}$ al millón de pesos. Ya en 1975, las industrias químicas ocupaban 125 mil personas que podrían duplicarse en los próximos años si se movilizan los flujos de capital.

No obstante, la composición profesional de la población ocupada es defectuosa. Apenas el 10\% de la misma tiene título académico (1974); y con buena suerte, puede llegar al 12 hacia finales del decenio. El peso de los profesionales es pobre si se tienen presentes la importancia estratégica de esta actividad y su potencial en México.

Las carencias del recurso humano -en las que los autores de esta importante obra no insisten suficientemente- se hacen patentes en el hecho de que de los 15 mil químicos que tiene México, apenas 800 se dedican a investigación y desarrollo. Es decir, pocos se dedican a la creación, impulso, y trasplante de innovaciones vitales; "la mayoría de los ingenieros químicos en México se dedican a la administración, a la operación de plantas, y a las ventas" (p. 75).

En este sentido, es importante el cuadro 6.3 (p. 75) que muestra los tipos de actividad del ingeniero químico en México y en Estados Unidos. Absoluta y relativamente la investigación pierde terreno en el primero.

¿Es una tergiversación de las compensaciones materiales e intangibles lo que ocasiona este defectuoso perfil profesional? ¿O bien se trata de una falta de comunicación entre universidad y mercado, oferta y demanda, instituciones presentes y requerimientos futuros? No tenemos respuestas satisfactorias a estas interrogantes.

A los autores les preocupa este asunto. Por ello dedican atención cuidadosa a la secuencia tecnológica que debe acompañar al desempeño químico y de los químicos. Sugieren el sistema IDIEP (investigación, desarrollo, ingeniería, fabricación de equipo, y producción) como un módulo conceptual y operativo para comprender y manejar la creación y el trasplante del cambio técnico en esta actividad. La propuesta es interesante, aunque excesivamente formalista. Puesto que parece suponer, de una parte, una excesiva linealidad en las etapas de la producción tecnológica, y, de otra, la existencia de un consenso inquebrantable entre gobierno, industria y universidad. Ambos supuestos deben ser revisados.

Y no me refiero en exclusiva a fenómenos macropolíticos que han distorsionado -cuando no cortado- la comunicación entre estos actores. Sugiero que una organización inadecuada de componentes que portan cargas desiguales de poder y que están animados por horizontes temporales también desiguales puede estropear el consenso, incluso si se revela en el plano global. 
De todos modos, la obra hace hincapié en la importancia considerable de la información tecno-química, pues segmentos amplios de la misma pueden todavía aprovecharse sin gastos mayores. También es de interés la idea que esbozan sobre los "módulos básicos" (p. 292) que ofrecen orientaciones sobre qué, dónde y cómo buscar conocimiento productivo.

Obviamente, la actividad química no es un quehacer "cerrado". Su forma y evolución están afectados por tendencias generales. Si a principios del siglo esta industria no llegaba a los 1000 millones de dólares, hoy supera los 150 mil millones. El crecimiento es altamente concentrado; entre las primeras 46 empresas en el mundo (que venden más de 1000 millones) ninguna es latinoamericana. Pemex apenas toca los 500 millones de dólares.

Para irrumpir en este mercado, países relativamente mayores y ricos como México deben resolver satisfactoriamente tres problemas básicos. Uno es de escala. Hay necesidad de encontrar "nichos" en el mercado químico internacional, descuidados por razones tecnológicas, financieras o estratégicas por las grandes empresas. Aferrándose a estos nichos, México podría escalar posiciones. Muy vinculada a esta restricción de escala se encuentra la vulnerabilidad nacional en investigación y desarrollo. Parece obvio que unos 800 ingenieros químicos dedicados a la misma son insuficientes. Cantidad y calidad deben incrementarse, con criterios más selectivos que los que han prevalecido hasta el presente. Y, por último, la competitividad en costos debe conseguirse, al principio con el auxilio flexible del Estado, y, más tarde, con el dinamismo intrínseco que vayan tomando las empresas. El argumento de "la industria infantil" debe ser reformulado, teniendo presente la extensión y el ritmo cambiante de las fronteras tecnológicas.

En suma, es éste un libro de consulta insoslayable no sólo para el químico o el tecnólogo; y no sólo para los mexicanos. Cualqier interesado en el desarrollo de sociedades de incipiente o fragmentaria industrialización, y que se empeñan en interiorizar los requisitos (capital, tecnología, flexibilidad) de las industrias contemporáneas, encontrará aquí vivas provocaciones intelectuales. Y no cualquier obra tiene esta virtud.

JOSEPH HODARA

Center for Technological Analysis and Forecasting - Tel Aviv University 